\title{
Publication of a Special Issue: Limb and Fin Regeneration
}

\author{
Claire Redhead \\ TheScientificWorld, UK \\ E-mail: credhead@thescientificworld.com
}

Published October 5, 2007

TheScientificWorldJOURNAL and TSW Development \& Embryology are delighted to have published the special issue 'Limb and Fin Regeneration', a collection of peer-reviewed papers covering key topics in this important field. The special issue has been organized by Dr. Marie-Andree Akimenko (Ottawa Health Research Institute, Ontario, Canada) and examines regeneration in a range of vertebrate species.

Specific topics covered are:

- Limb regeneration in amphibians: Immunological considerations

- Limb regeneration in Axolotl: Is it superhealing?

- Limb regeneration in Xenopus laevis froglet

- Transcriptional profiling of caudal fin regeneration in Zebrafish

- Newt opportunities for understanding the dedifferentiation process

- Comparative experimental analysis of fin lepidotrichia in fishes and several skeletal tissues in vertebrates including humans

The Publisher wishes to express thanks to all of the authors and reviewers, and especially to acknowledge the contribution of Dr. Akimenko in bringing about the publication of these papers.

This article should be cited as follows:

Redhead, C. (2007) Publication of a special issue: Limb and Fin Regeneration. TheScientificWorldJOURNAL: TSW Development \& Embryology 7, 1617. DOI 10.1100/tsw.2007.3. 

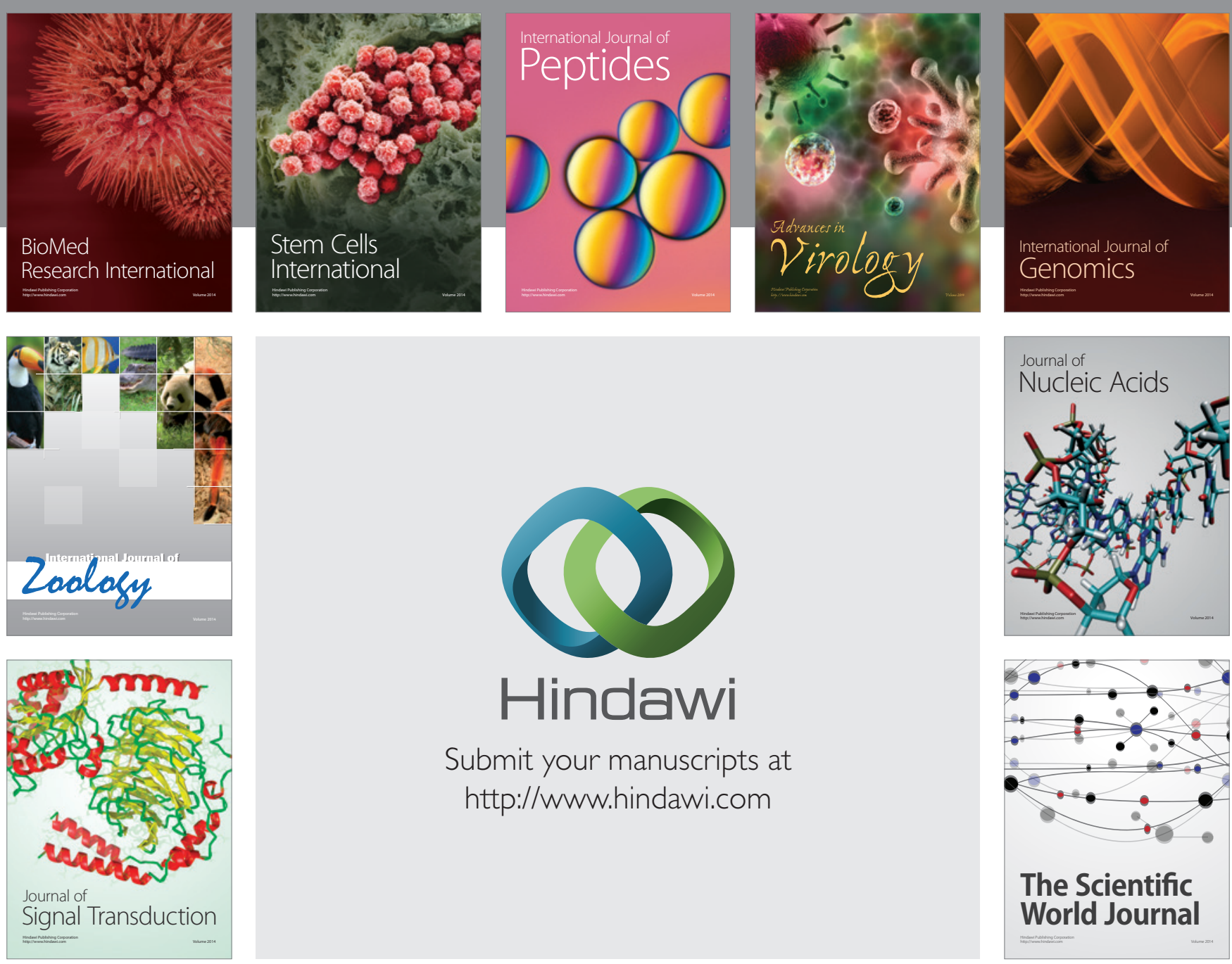

Submit your manuscripts at

http://www.hindawi.com
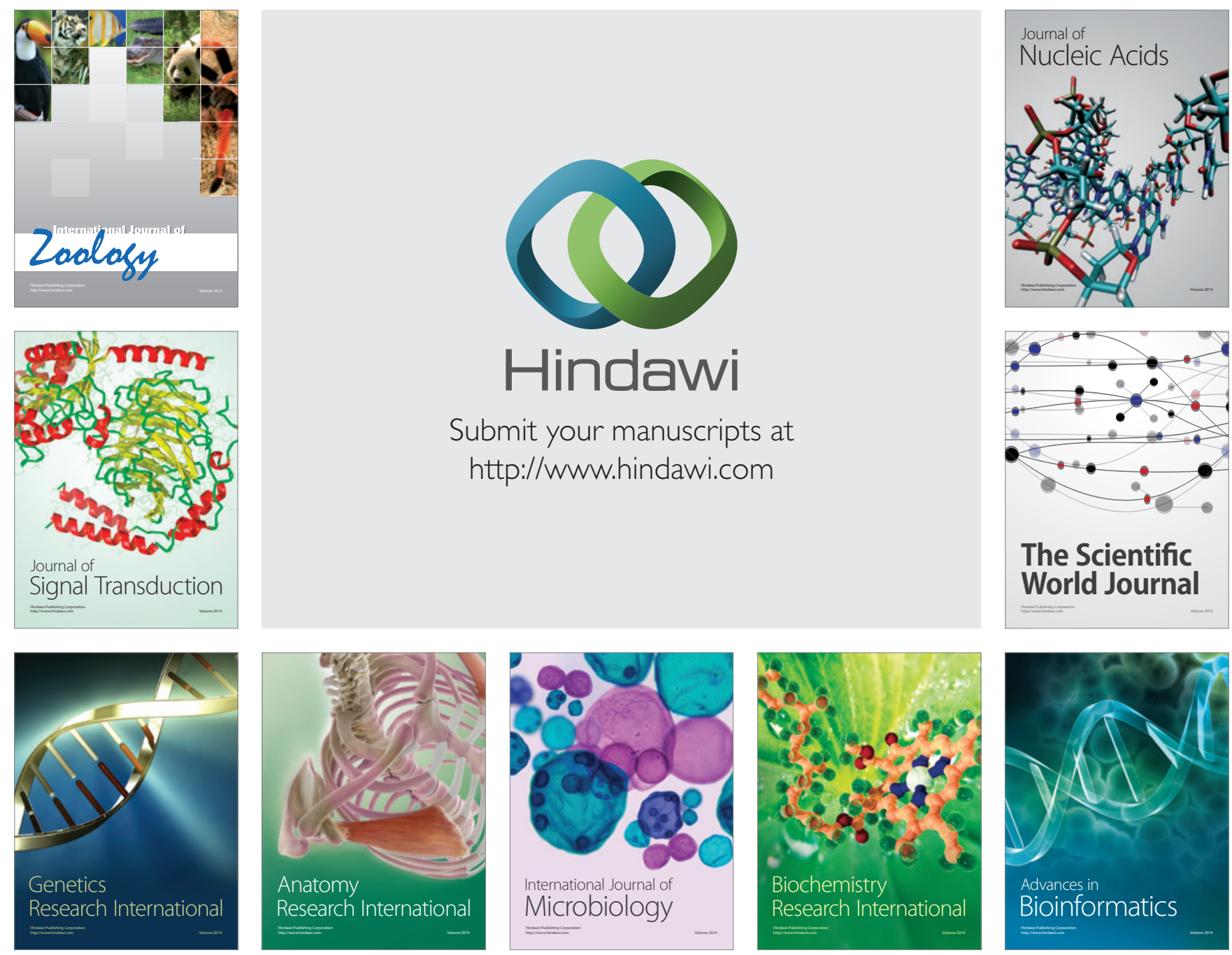

The Scientific World Journal
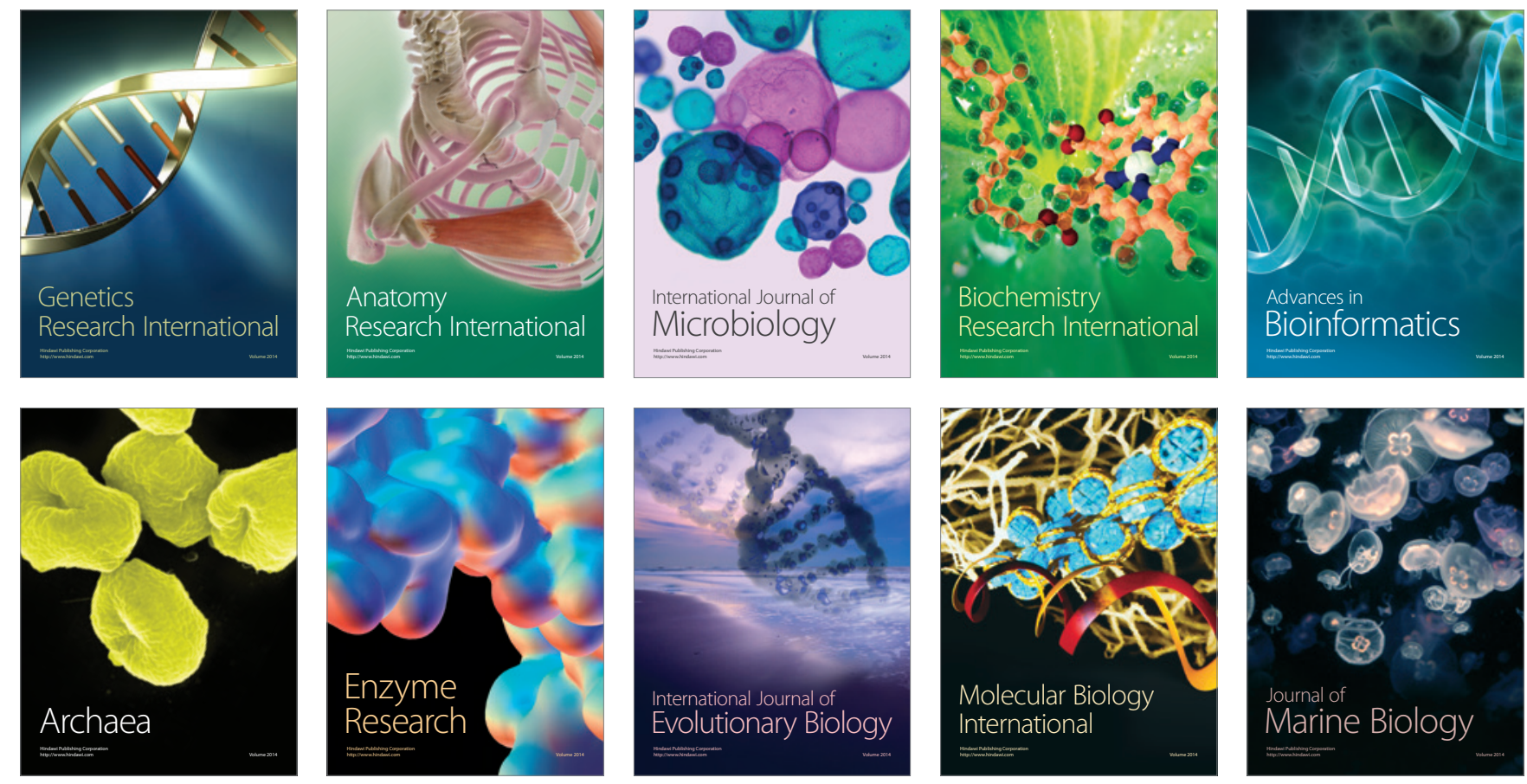